\title{
Eritropoietina Sérica como Marcador Prognóstico em Síndrome Mielodisplásica
}

\author{
Serum Erythropoietin as Prognostic Marker in Myelodysplastic Syndromes
}

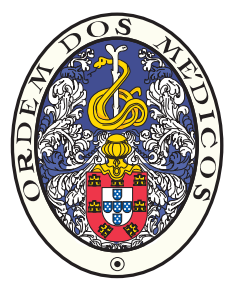

\author{
Emília CORTESÃO ${ }^{1,3,5}$, Rita TENREIRO ${ }^{1}$, Sofia RAMOS ${ }^{1}$, Marta PEREIRA ${ }^{1,5}$, Paula CÉSAR ${ }^{1}, J^{4}$ Sé P. CARDA ${ }^{1,5}$, \\ Marília GOMES ${ }^{1,5}$, Luís RITO ${ }^{1,5}$, Emília MAGALHÃES ${ }^{1}$, Ana C. GONÇALVES ${ }^{3,5}$, Nuno C. e SILVA ${ }^{4,5}$, Catarina \\ GERALDES ${ }^{1,3,5}$, Amélia PEREIRA ${ }^{6}$, Letícia RIBEIRO'1, José M. NASCIMENTO COSTA ${ }^{2,3,5}$, Ana B. Sarmento RIBEIRO ${ }^{1,3,5}$ \\ Acta Med Port 2015 Nov-Dec;28(6):720-725
}

\section{RESUMO}

Introdução: A síndrome mielodisplásica é uma doença heterogénea caracterizada por displasia, medula hipercelular, citopenias e risco de evolução para leucemia aguda. Outros factores de prognóstico, nomeadamente, fibrose medular, elevação da enzima desidrogenase do lactato e $\beta 2$-microglobulina têm sido descritos, contudo, a decisão terapêutica baseia-se no score do International Prognostic Scoring System.

Material e Métodos: Este trabalho teve como objectivo analisar a relevância da eritropoietina sérica ao diagnóstico, em doentes com síndrome mielodisplásica de novo, avaliando o seu impacto na sobrevivência global e a sua implementação como factor de prognóstico. Recolhemos dados clínicos e laboratoriais de 102 doentes com síndrome mielodisplásica de novo diagnosticada entre outubro/2009 e março/2014. A análise de sobrevivência foi efectuada recorrendo à metodologia de Kaplan-Meier, de acordo com os valores de eritropoietina.

Resultados: A amostra, de 102 doentes, apresenta uma mediana de idades de 74 anos e relação masculino/feminino igual a 0,8. Os doentes com o subtipo citopenia refratária com displasia unilinha apresentam, em média, valores de eritropoietina significativamente mais baixos, em oposição aos doentes com o subtipo $5 q$ - que apresentam a média de eritropoietina sérica mais elevada $(p<0,05)$. Onze doentes evoluíram para leucemia aguda; estes têm, em média, eritropoietina sérica superior $(p<0,05)$. Adicionalmente, a eritropoietina sérica acima do limite superior da normalidade associa-se a menor sobrevivência $(p=0,0336)$. Após ajuste do modelo de regressão de Cox, o valor preditivo da eritropoietina para a sobrevivência global manteve-se $(p<0,001)$. Em análise multivariada, a eritropoietina sérica demonstrou ser um factor de prognóstico independente $(p<0,001)$.

Discussão: A eritropoietina sérica é um factor preditivo de resposta à terapêutica com eritropoietina subcutânea, sendo que os doentes com síndrome mielodisplásica com valores mais elevados de eritropoietina apresentam uma pior resposta à administração de eritropoietina, mesmo com doses mais elevadas. A nossa amostra demonstra que a eritropoietina sérica apresenta também valor prognóstico, e em todos os subtipos de síndrome mielodisplásica. Além disso, isoladamente ou em associação com outros factores ou índices de prognóstico, poderá melhorar o valor prognóstico de índices como o International Prognostic Scoring System, uma vez que valores elevados de eritropoietina estão associados a progressão para leucemia aguda e, consequentemente, a menor sobrevivência. Conclusão: Os resultados sugerem que o aumento dos níveis séricos de eritropoietina ao diagnóstico pode constituir um factor de mau prognóstico em doentes com síndrome mielodisplásica, associando-se a maior risco de evolução para leucemia aguda e menor sobrevivência global.

Palavras-chave: Eritropoietina; Prognóstico; Síndrome Mielodisplásica.

\section{ABSTRACT}

Introduction: This myelodysplastic syndromes are a heterogeneous entity characterized by dysplasia, hypercellular bone marrow, cytopenias and risk of transformation to acute leukaemia. Prognostic factors, such as bone marrow fibrosis, lactate dehydrogenase and $\beta 2$-microglobulin elevation have been described, but treatment is mainly based in the International Prognostic Scoring System.

Material and Methods: Our aim was to analyze serum's erythropoietin at diagnosis in de novo myelodysplastic syndromes patients, through its impact in overall survival and possible implementation as prognostic marker. Clinical and laboratorial data from 102 patients with de novo myelodysplastic syndromes diagnosed between October/2009 and March/2014 were collected. Survival analysis was performed according to serum erythropoietin level stratification, using Kaplan-Meier methodology.

Results: Our 102 patients had a median age of 74 years, with a male:female ratio of 0.8 . Mean erythropoietin was significantly lower in refractory cytopenia with unilineage dysplasia patients in contrast with the higher values observed in $5 q-$ syndrome $(p<0.05)$. Eleven patients progressed to acute leukaemia; these have higher mean erythropoietin values $(p<0.05)$. In addition, elevated serum erythropoietin was associated with lower survival rates $(p=0.0336)$. Predictive value of serum erythropoietin was maintained after Cox regression adjustment. In multivariate analysis, serum erythropoietin is an independent survival predictor $(p<0.001)$.

Discussion: Serum erythropoietin is a predictive factor for response to therapy with subcutaneous erythropoietin, and patients with myelodysplastic syndromes with higher values of erythropoietin have poorer response to administration of erythropoietin even at higher doses. Our sample shows that serum erythropoietin also has prognostic value, and in all myelodysplastic syndromes subtypes.

1. Serviço de Hematologia Clínica. Centro Hospitalar e Universitário de Coimbra. Coimbra. Portugal.

2. Serviço de Oncologia. Centro Hospitalar e Universitário de Coimbra. Coimbra. Portugal.

3. Centro de Investigação em Meio Ambiente, Genética e Oncobiologia. Coimbra. Portugal.

4. Serviço de Patologia Clínica. Centro Hospitalar de Coimbra. Coimbra. Portugal.

5. Faculdade de Medicina. Universidade de Coimbra. Coimbra. Portugal.

6. Serviço de Medicina Interna. Hospital Distrital da Figueira da Foz. Figueira da Foz. Portugal.

$\square$ Autor correspondente: Rita Tenreiro. ritatenreiro.pt@gmail.com

Recebido: 15 de Abril de 2015 - Aceite: 10 de Agosto de 2015 | Copyright @ Ordem dos Médicos 2015 
Moreover, alone or in combination with other factors or prognostic indices, erythropoietin may enhance the prognostic indices such as the International Prognostic Scoring System, since high levels are associated with progression to acute leukemia and hence lower survival.

Conclusion: This study suggests that increased erythropoietin levels at diagnosis can by itself be a poor prognosis factor in myelodysplastic syndromes patients, with higher values in patients with progression to acute leukaemia and decreased overall survival. Keywords: Erythropoietin; Myelodysplastic Syndromes; Prognosis.

\section{INTRODUÇÃO}

A síndrome mielodisplásica (SMD) é uma doença clonal da célula estaminal hematopoiética caracterizada por displasia celular, hematopoiese ineficaz com citopenia(s) periférica(s), mas com medula hipercelular, e proliferação anormal de blastos. Esta patologia está associada a elevado risco de progressão para leucemia aguda com sobrevivência global baixa e resistência às terapêuticas convencionais.

Actualmente, a decisão da terapêutica a instituir é baseada na aplicação de scores de prognóstico, sendo o mais amplamente utilizado e validado, o International Prognosis Scoring System (IPSS). ${ }^{1}$ Para além dos parâmetros que constituem este índice de prognóstico (número de citopenias, percentagem de blastos e cariótipo), outros factores de prognóstico têm sido descritos na literatura, nomeadamente, a presença de fibrose medular, a dependência transfusional, a presença de clusters de células $\mathrm{CD} 34+$, a elevação da desidrogenase do lactato $(\mathrm{LDH})^{2} \mathrm{e}$ ß2-microglobulina, e mais recentemente, as mutações genéticas e/ou epigenéticas. ${ }^{3}$ Nos últimos anos, o crescente conhecimento científico nesta área permitiu a elaboração de novos scores de prognóstico: o World Health Organization (WHO) Prognostic Scoring System (WPSS) 4 e o Revised International Prognostic Scoring System (IPSS-R), ${ }^{5}$ que pela sua complexidade crescente têm dificultado a sua implementação na prática clínica diária.

Apesar do benefício da terapêutica com factores de crescimento, nomeadamente da eritropoietina e do fator de crescimento estimulante das colónias de granulócitos (EPO $\pm G-C S F)$, ter sido demonstrado em estudos retrospectivos, bem como dos níveis séricos de EPO (<500 IU/L) serem considerados em vários estudos como preditivos de resposta, a EPO sérica não demonstrou impacto na evolução para leucemia aguda. ${ }^{6-10}$

Além disso, o papel dos níveis de EPO como factor de risco prognóstico na SMD não foi ainda estabelecido.

O objectivo deste trabalho foi analisar a relevância da eritropoietina sérica ao diagnóstico, numa amostra de doentes com SMD de novo, avaliando o seu impacto na evolução para LMA e na sobrevivência global dos doentes, de modo a determinar a sua potencial implementação como factor de prognóstico.

\section{MATERIAL E MÉTODOS}

Procedemos à recolha de dados clínicos e laboratoriais de doentes diagnosticados com SMD de novo entre o período de Outubro de 2009 e Março de 2014. Os estudos foram efetuados em amostras de sangue periférico e medula óssea, recolhidos durante os procedimentos de diagnóstico, ao longo de 55 meses, após aprovação do consenti- mento informado, pela Comissão de Ética Hospitalar.

Em todos os doentes foram recolhidos os parâmetros hematológicos disponibilizados no hemograma, por citometria e citologia (leucócitos, neutrófilos, monócitos, hemoglobina, plaquetas), e os seguintes parâmetros bioquímicos: doseamentos séricos de ferritina, LDH e eritropoietina.

Utilizando a classificação da Organização Mundial de Saúde (OMS) de 2008, os doentes foram incluídos no respectivo grupo e a avaliação do prognóstico foi efetuada mediante a aplicação do IPSS.

A análise de sobrevivência foi efectuada por regressão logística (análise multivariada) tendo em atenção os níveis séricos de eritropoietina. Os doentes foram divididos em cinco subgrupos: valores de eritropoietina sérica inferiores ao normal, normais, superiores ao normal e inferiores a 100 $\mathrm{mUl} / \mathrm{mL}$, entre $100-500 \mathrm{mUl} / \mathrm{mL}$ e finalmente valores superiores a $500 \mathrm{mUl} / \mathrm{mL}$. A sobrevivência global foi calculada recorrendo à metodologia de Kaplan-Meier e as diferenças foram avaliadas pelos métodos de Log-rank e Wilcoxon, considerando um valor com significância estatística para um $p<0,05$.

As curvas receiver operating characteristic (ROC) permitiram avaliar se o parâmetro bioquímico em estudo, eritropoietina sérica, permite discriminar os doentes que evoluíram para leucemia aguda dos outros.

\section{RESULTADOS}

A nossa amostra é constituída por 102 doentes de raça caucasiana com o diagnóstico de SMD de novo. Os doentes têm uma mediana de idades de 74 anos (22 - 89 anos). A distribuição por sexos revela um maior número de doentes do sexo feminino (58 doentes) em comparação com o número de doentes do sexo masculino (44 doentes) com uma relação masculino/feminino de 0,8 .

Os subtipos de SMD segundo a OMS distribuem-se da seguinte forma: citopenia refratária com displasia multilinha (CRDM) (52 doentes), citopenia refratária com displasia unilinha (CRDU) (12 doentes), anemia refratária com excesso de blastos (AREB)-1 (oito doentes), AREB-2 (oito doentes), anemia refratária com sideroblastos em anel (seis doentes), síndrome 5q- (quatro doentes) e leucemia mielomonocítica crónica (LMMC) (12 doentes) (Fig. 1A).

Para a determinação do IPSS foram utilizados os fatores de prognóstico descritos na literatura, isto é, a percentagem de blastos na medula, as alterações citogenéticas e o número de citopenias. ${ }^{1}$ Este score permitiu a distribuição dos doentes com citogenética conclusiva ( 87 doentes), em quatro categorias de risco: baixo (37 doentes), intermédio-1 (39 doentes), intermédio-2 (10 doentes) e alto (um doente) (Fig. 1B). 

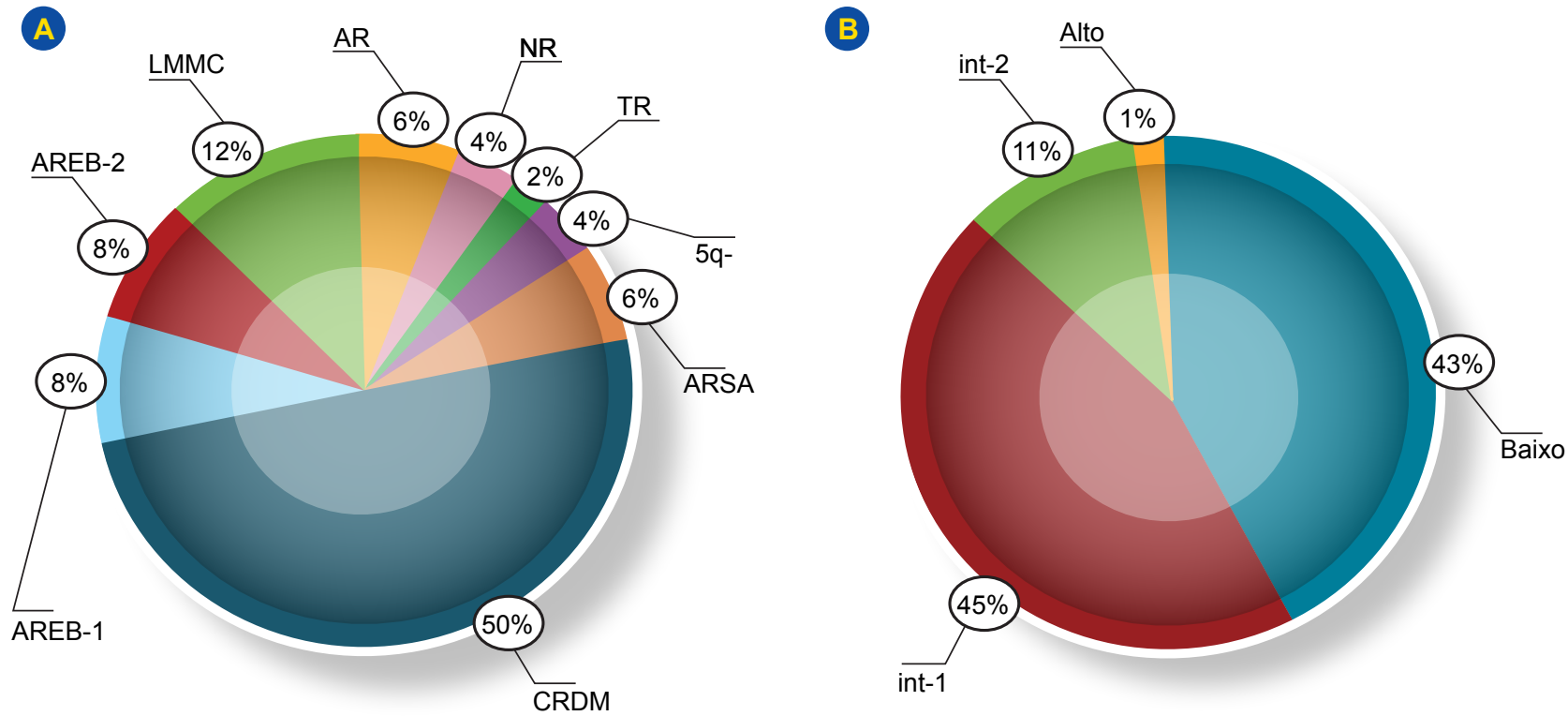

Figura 1 - Distribuição dos doentes de acordo com a classificação da Organização Mundial de Saúde 2008 (A) e com o International Prognostic Scoring System (B)

Aplicámos ainda o IPSS-R, ${ }^{5}$ para o qual foram utilizados os seguintes parâmetros: citogenética, percentagem de blastos medulares, valores de hemoglobina, plaquetas e neutrófilos, estabelecendo, deste modo cinco grupos de risco englobando 86 doentes: 20 doentes de muito baixo risco, 32 doentes de baixo risco, 19 doentes de risco intermédio, 12 doentes de alto risco e três doentes de muito alto risco. Em 16 doentes não foram aplicados estes scores por citogenética inconclusiva $(n=15)$ ou doentes com LMMC com contagem de leucócitos superior a $12 \mathrm{G} / \mathrm{L}(\mathrm{n}=1)$.

O WPSS ${ }^{4}$ contempla a análise citogenética, bem como o subtipo de SMD segundo a classificação da OMS e a ne-

A

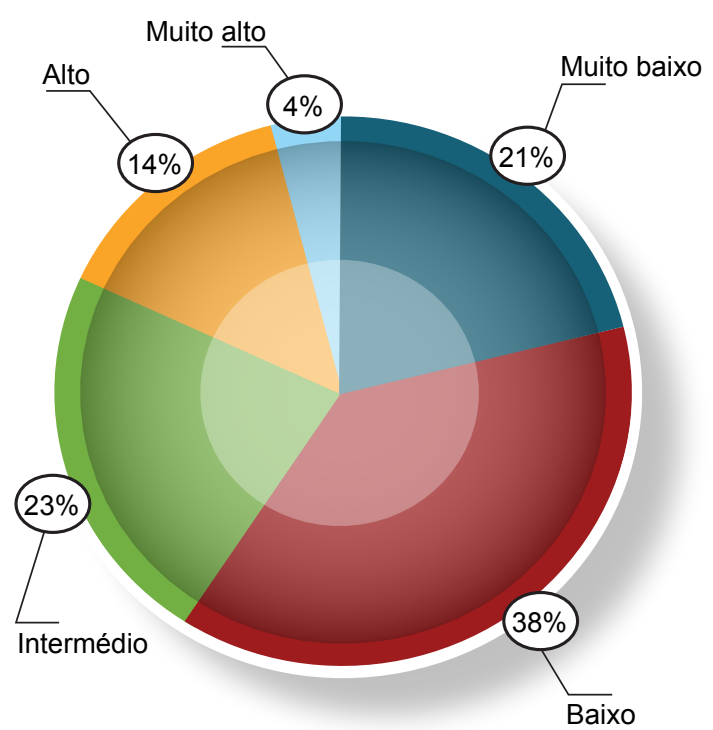

cessidade transfusional. De acordo com este índice, dividimos a amostra em cinco grupos: muito baixo (16 doentes), baixo ( 27 doentes), intermédio ( 20 doentes), alto (13 doentes) e muito alto (um doente). À semelhança dos scores anteriores, a citogenética inconclusiva ou diagnóstico de LMMC não permitiram a aplicação do WPSS em 25 doentes (Fig.s 2A e 2B).

Relativamente aos doseamentos de eritropoietina sérica, verificou-se a presença de uma média dos valores de eritropoietina sérica elevada nos doentes com síndrome 5q- (164 $\mathrm{mUl} / \mathrm{mL})$ e reduzida nos doentes com o subtipo neutropenia refractária (NR) $(9 \mathrm{mUl} / \mathrm{mL})$, em comparação

B

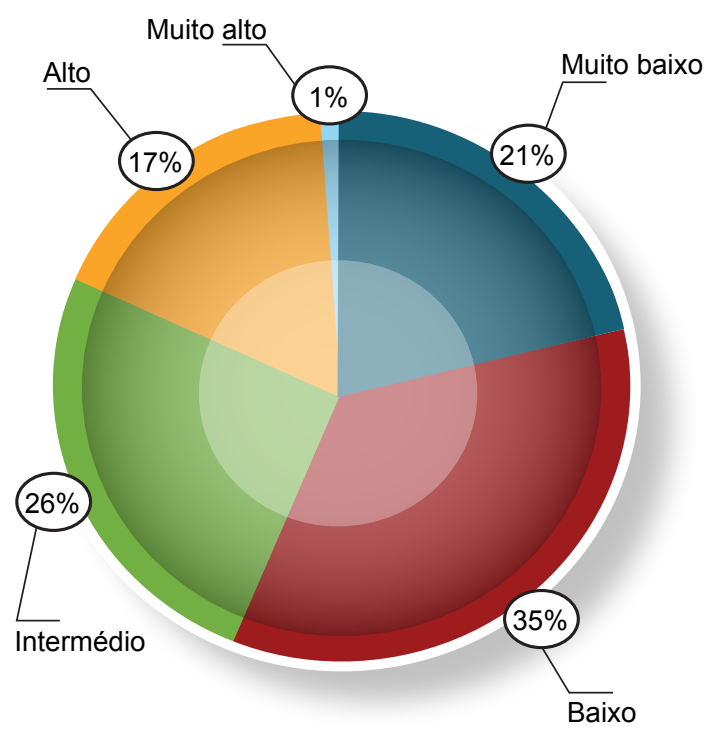

Figura 2 - Caracterização da população de doentes com síndrome mielodisplásica segundo o International Prognostic Scoring System-Revised (A) e o World Health Organization (WHO) Prognostic Scoring System (B) 
com os doentes dos outros subtipos da OMS $(p<0,05)$ (Fig. 3).

Do total da amostra de 102 doentes, 11 evoluíram para LMA, sendo este subgrupo constituído por sete doentes com AREB-2, dois com CRDM, um com AREB-1 e outro doente com LMMC. De salientar que os doentes que progrediram para LMA apresentam, em média, um nível sérico de eritropoietina superior. Verificou-se diferença estatística entre os indivíduos com evolução para LMA para valores de eritropoietina sérica superiores a $57,45 \mathrm{mUl} / \mathrm{mL}(p<0,05)$ (Tabela 1).

Analisámos a sobrevivência global (OS) dos 102 doentes com SMD e verificámos que aos 23 meses de follow-up $50 \%$ dos doentes estavam vivos, e aos 36 meses apenas $32 \%$ dos doentes permanecia em seguimento. O grupo de 11 doentes que evoluiu para LMA apresenta uma taxa de sobrevivência inferior ao grupo que não progrediu, comprovado por um $p<0,01$.

A análise da sobrevivência, tendo em atenção os níveis séricos de eritropoietina, permitiu a divisão em cinco grupos de acordo com o valor apresentado: valores de eritropoietina sérica inferiores ao normal (dois doentes), normais (42 doentes), superiores ao normal e inferiores a $100 \mathrm{mUl} /$ $\mathrm{mL}$ (30 doentes), entre $100-500 \mathrm{mUl} / \mathrm{mL}$ (nove doentes) e valores superiores a $500 \mathrm{mUl} / \mathrm{mL}$ (dois doentes). Verificámos diferença estatisticamente significativa na sobrevivência para a eritropoietina sérica ( $p=0,0336)$, ou seja, os doentes que apresentam valores acima do limite superior da normalidade (41 doentes), têm uma sobrevivência inferior aos doentes com valores dentro da normalidade (44 doentes) (Fig. 4).
Após ajuste do modelo de regressão de Cox para LDH, idade, IPSS, IPSS-R, hemoglobina, neutrófilos, plaquetas, ferritina, $\beta 2$-microglobulina e blastos medulares, o valor preditivo da eritropoietina na sobrevivência global manteve-se. Em regressão multivariada, a eritropoietina foi preditor de sobrevivência $(p<0,001)$.

\section{DISCUSSÃO}

$\mathrm{O}$ estudo decorreu ao longo de 55 meses e englobou 102 doentes com SMD de novo, os quais apresentam uma idade mediana de 74 anos, com uma relação masculino/ feminino de 0,8. Estes dados estão de acordo com os disponíveis na literatura, embora a maior parte dos estudos, refira um ligeiro predomínio do sexo masculino. ${ }^{10,11}$

Relativamente à distribuição dos doentes pelos subtipos da OMS de 2008, verificámos um predomínio de doentes com citopenias refratárias numa percentagem superior à descrita na literatura, destacando-se o subtipo CRDM. ${ }^{12,13}$ Inversamente, a percentagem de doentes com anemias refratárias com excesso de blastos (AREBs) e com LMMC é inferior ao referido por outros autores, enquanto os subtipos síndrome $5 q$ - e ARSA, estão de acordo com a literatura. ${ }^{12-15}$

Esta distribuição por subtipos permite uma previsão relativamente aos grupos de prognóstico, ou seja, o predomínio de doentes com SMD em estádios iniciais corresponde a doentes com índices de prognóstico baixos e intermédios. Assim, a distribuição segundo o IPSS divide a nossa população em $87 \%$ de doentes de baixo risco (incluindo o risco baixo e intermédio-1), o que demonstra um predomínio de doentes de baixo risco em relação aos $70 \%$ descritos na literatura. ${ }^{1}$

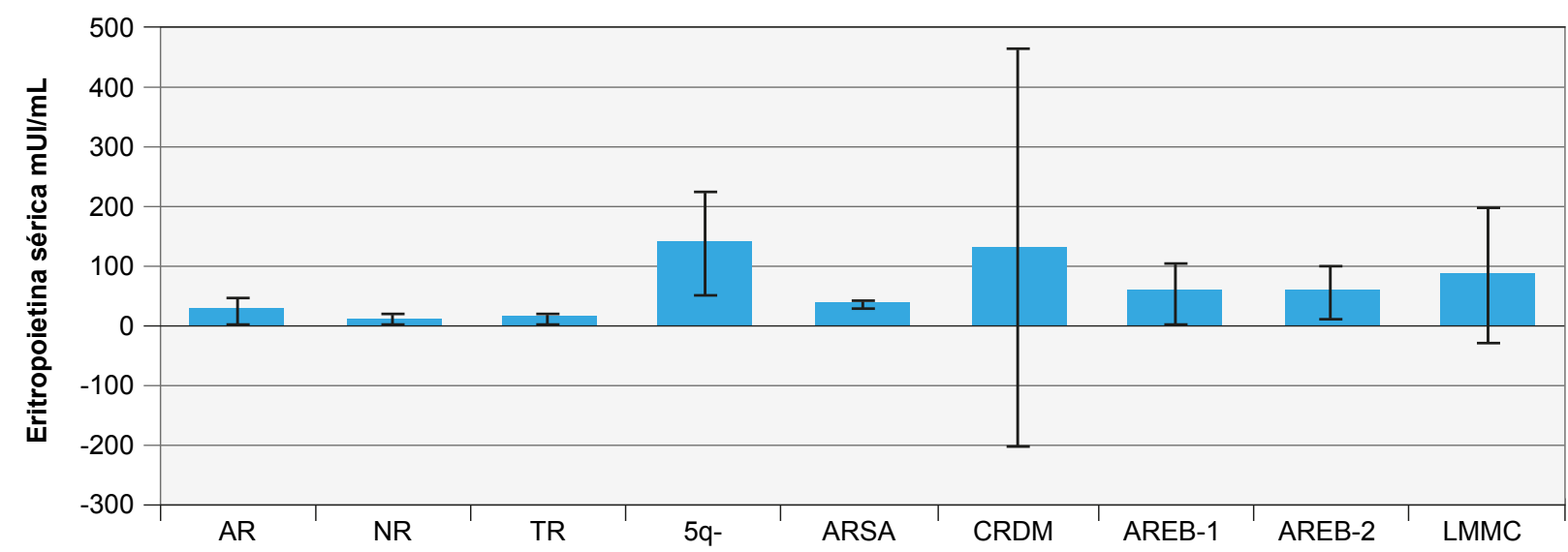

Figura 3 - Valores séricos de eritropoietina nos doentes com síndrome mielodisplásica, segundo os subtipos da Organização Mundial de Saúde

${ }^{*} p<0,05 ;$ AR: Anemia refractária; NR: Neutropenia refractária; TR: Trombocitopenia refractária.

Tabela 1 - Curvas receiver operating characteristic (ROC)

\begin{tabular}{ccccccc} 
& IC (95\%) & p value & Cut-off & Sensibilidade & Especificidade & Área abaixo da curva \\
\hline EPO & $0,518-0,883$ & 0,032 & 57,45 & $73 \%$ & $80 \%$ & 0,7
\end{tabular}

Nota: VPP (valor preditivo positivo) $64 \%$; VPN (valor preditivo negativo) $81 \%$.

EPO: Eritropoietina; IC: Intervalo de confiança. 


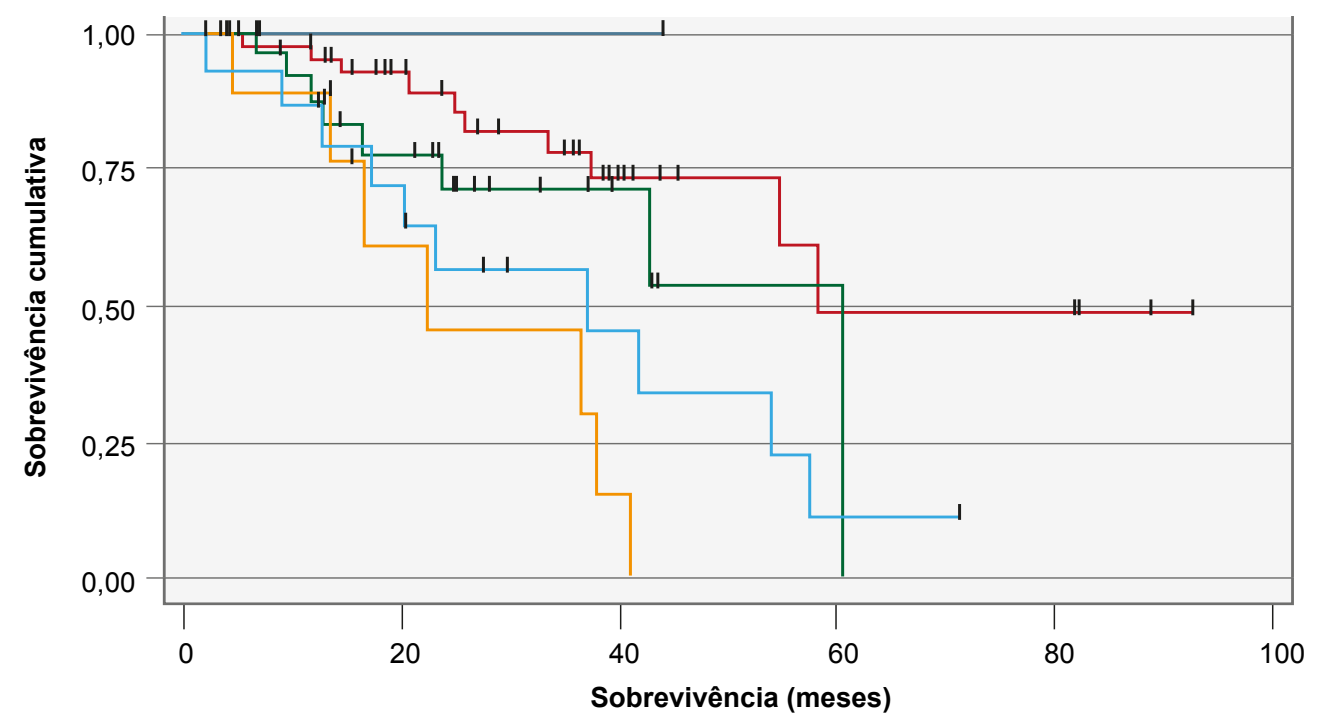

Epo baixa

Epo normal

Epo elevada (< $100 \mathrm{U} / \mathrm{L})$

Epo elevada (100 - $500 \mathrm{U} / \mathrm{L})$

Epo elevada ( $\geq 500 \mathrm{U} / \mathrm{L})$

Figura 4 - Relação entre a eritropoietina sérica e a sobrevivência global

Além do IPSS e de outros scores de prognóstico (IPSS-R e WPSS), têm sido identificados outros parâmetros preditivos de prognóstico, nomeadamente a presença de fibrose medular, os níveis séricos de LDH e de $\beta 2$ microglobulina. ${ }^{2,5}$

O doseamento dos níveis séricos de eritropoietina, até ao momento, tem sido utilizado como um parâmetro fundamental na decisão terapêutica, não estando ainda estabelecido o seu papel como marcador de prognóstico. ${ }^{6-9}$

Neste sentido, fomos avaliar a relevância dos níveis de eritropoietina sérica ao diagnóstico como marcador de prognóstico em doentes com SMD de novo.

Os nossos resultados mostram que os doentes dos vários subtipos de SMD de acordo com OMS 2008 apresentam diferenças estatisticamente significativas no valor de eritropoietina sérica ao diagnóstico e que este se relacionada com a sobrevivência.

Independentemente da divisão dos valores de eritropoietina por subgrupos (inferior ao normal, normal, elevado, mas inferior a $100 \mathrm{mUl} / \mathrm{mL}$, entre $100-500 \mathrm{mUl} / \mathrm{mL}$ e superior a $500 \mathrm{mUl} / \mathrm{mL}$ ), os doentes com valores de eritropoietina sérica acima do limite superior da normalidade (superior a $29 \mathrm{mUl} / \mathrm{mL}$ ) apresentam uma sobrevivência inferior $(p=0,0336)$. O seu valor preditivo manteve-se após ajuste do modelo de regressão de Cox para LDH, idade, IPSS, IPSS-R, hemoglobina, neutrófilos, plaquetas, ferritina, $\beta 2-$ microglobulina e blastos medulares. A análise multivariada identificou a eritropoietina como um factor preditivo da sobrevivência global $(p<0.001)$ demonstrando ser um factor de prognóstico independente em SMD. Além disso, verificámos que os níveis séricos de eritropoietina superiores a $57,45 \mathrm{mUI} / \mathrm{mL}$ influenciam a progressão para leucemia aguda, sugerindo a relevância da eritropoietina como eventual marcador de progressão.

Nos últimos anos, o valor da eritropoietina nas SMD tem vindo a ser explorado na literatura como factor preditivo de resposta à EPO. Neste momento sabemos que os doentes com SMD com valores mais elevados de eritropoietina apresentam uma pior resposta à administração de eritropoietina, mesmo com doses mais elevadas. ${ }^{16-19}$ Além da importância da eritropoietina sérica como um indicador de resposta à terapêutica com eritropoietina, ${ }^{6,8,9} \mathrm{em} 2002$, o valor prognóstico da eritropoietina, foi descrito, numa série de 68 doentes em que se incluíam doentes com anemia refractária (AR), ARSA e AREB. ${ }^{20}$ A nossa amostra alarga estas conclusões a todos os subtipos de SMD, numa amostra maior de doentes estudados, identificando um papel prognóstico para a eritropoietina.

Além disso, isoladamente ou em associação com outros factores ou índices de prognóstico, à semelhança do descrito para a $\mathrm{LDH},{ }^{2}$ poderá melhorar o valor prognóstico de índices como o IPSS.

Com este trabalho, o papel da eritropoietina como preditor de sobrevivência global e de progressão para LA adquire uma nova expressão, sugerindo a sua importância como fator de prognóstico que poderá eventualmente ser implementado na prática clínica diária.

\section{CONCLUSÃO}

Este trabalho vem demonstrar a importância da eritropoietina sérica ao diagnóstico como factor de prognóstico independente numa série de 102 doentes com SMD de novo. A análise de parâmetros bioquímicos permitiu identificar a eritropoietina como fator de mau prognóstico, quando elevada, estando associada aos doentes que evoluíram para LMA e a taxas de sobrevivência inferiores.

A recente introdução de novos índices de prognóstico e a inclusão de mutações genéticas específicas aumentaram a complexidade de avaliação prognóstica, tornando difícil a sua implementação por falta de recursos para realização de tais estudos genéticos em todos os centros e aumentando os custos associados à saúde. Apesar da utilidade na prática clínica destes sistemas de pontuação, verificamos que dentro do mesmo grupo de estratificação de risco, 
alguns doentes apresentam evolução particularmente desfavorável, sugerindo a existência de factores de prognóstico não englobados nestes sistemas. Serão ainda necessários mais estudos para afirmar definitivamente o valor prognóstico da eritropoietina, englobando maior número de doentes e até estabelecendo correlações com mutações genéticas já conhecidas. Este trabalho coloca em questão se alguns factores de prognóstico não poderão ainda estar ocultos em parâmetros diariamente utilizados na prática clínica e facilmente acessíveis em todos os centros.

\section{PROTECÇÃO DE PESSOAS E ANIMAIS}

O presente estudo teve aprovação da Comissão de Ética do Centro Hospitalar e Universitário de Coimbra para ser realizado.

\section{REFERÊNCIAS}

1. Greenberg P, Cox C, LeBeau MM, Fenaux P, Morel P, Sanz G, et al. International scoring system for evaluating prognosis in myelodysplastic syndromes. Blood. 1997;89:2079-88.

2. Germing $U$, Hildebrandt $B$, Pfeilstöcker $M$, Nösslinger $T$, Valent $P$, Fonatsch $\mathrm{C}$, et al. Refinement of the international prognostic scoring system (IPSS) by including LDH as an additional prognostic variable to improve risk assessment in patients with primary myelodysplastic syndromes (MDS). Leukemia. 2005;19:2223-31.

3. Zhang L, Padron E, Lancet J. The molecular basis and clinical significance of genetic mutations identified in myelodysplastic syndromes. Leuk Res. 2015;39:6-17.

4. Malcovati L, Germing U, Kuendgen A, Della Porta MG, Pascutto C, Invernizzi R, et al. Time-dependent prognostic scoring system for predicting survival and leukemic evolution in myelodysplastic syndromes. J Clin Oncol. 2007;25:3503-10.

5. Greenberg PL, Tuechler H, Schanz J, Sanz G, Garcia-Manero G, Solé $F$, et al. Revised international prognostic scoring system for myelodysplastic syndromes. Blood. 2012;120:2454-65.

6. Hellström-Lindberg E, Negrin R, Stein R, Krantz S, Lindberg G, Vardiman $\mathrm{J}$, et al. Erythroid response to treatment with G-CSF plus erythropoietin for the anaemia of patients with myelodysplastic syndromes: proposal for a predictive model. Br J Haematol. 1997;99:344-51.

7. Jadersten M, Malcovati L, Dybedal I, Della Porta MG, Invernizzi R, Montgomery SM, et al. Erythropoietin and granulocyte-colony stimulating factor treatment associated with improved survival in myelodysplastic syndrome. J Clin Oncol. 2008;26:3607-13.

8. Santini V. Clinical use of erythropoietic stimulating agents in myelodysplastic syndromes. Oncologist. 2011;16:S35-42.

9. Park S, Grabar S, Kelaidi C, Beyne-Rauzy O, Picard F, Bardet V, et al. Predictive factors of response and survival in myelodysplastic syndrome treated with erythropoietin and G-CSF: the GFM experience. Blood. 2008;111:574-582.

10. Ma X, Does M, Raza A, Mayne ST. Myelodysplastic syndromes:

\section{CONFIDENCIALIDADE DOS DADOS}

Os autores declaram ter seguido os protocolos do seu centro de trabalho acerca da publicação dos dados de doentes.

\section{CONFLITOS DE INTERESSE}

Os autores declaram não ter nenhum conflito de interesses relativamente ao presente artigo.

\section{FONTES DE FINANCIAMENTO}

Não existiram fontes externas de financiamento para a realização deste artigo.

incidence and survival in the United States. Cancer. 2007;109:1536-42.

11. Ma X, Selvin S, Raza A, Foti K, Mayne ST. Clustering in the incidence of myelodysplastic syndromes. Leuk Res. 2007;31:1683-6.

12. Germing U, Strupp C, Kuendgen A, Isa S, Knipp S, Hildebrandt B, et al. Prospective validation of the WHO proposals for the classification of myelodysplastic syndromes. Haematologica. 2006;91:1596-604.

13. Malcovati L, Della Porta MG, Pascutto C, Invernizzi R, Boni M, Travaglino $\mathrm{E}$, et al. Prognostic factors and life expectancy in myelodysplastic syndromes classified according to WHO criteria: a basis for clinical decision making. J Clin Oncol. 2005;23:7594-603.

14. Breccia M, Carmosino I, Biondo F, Mancini M, Russo E, Latagliata R, et al. Usefulness and prognostic impact on survival of WHO reclassification in FAB low risk myelodyplastic syndromes. Leuk Res. 2006;30:178-82.

15. Williamson PJ, Kruger AR, Reynolds PJ, Hamblin TJ, Oscier DG Establishing the incidence of myelodysplastic syndrome. $\mathrm{Br} \mathrm{J}$ Haematol. 1994;87:743-5

16. Filì C, Malagola M, Follo MY, Finelli C, lacobucci I, Martinelli G, et al. Prospective phase II Study on 5-days azacitidine for treatment of symptomatic and/or erythropoietin unresponsive patients with low/INT1-risk myelodysplastic syndromes. Clin Cancer Res. 2013;19:3297-308.

17. Nakazaki K, Nannya Y, Kurokawa M. Distribution of serum erythropoietin levels in lower risk myelodysplastic syndrome cases with anemia. Int J Hematol. 2014;99:53-6.

18. Santini V. The quest for the perfect MDS scoring system. Leuk Res. 2012;36:125-6.

19. Spinelli E, Caporale R, Buchi F, Masala E, Gozzini A, Sanna A, et al. Distinct signal transduction abnormalities and erythropoietin response in bone marrow hematopoietic cell subpopulations of myelodysplastic syndrome patients. Clin Cancer Res. 2012;18:3079-89.

20. Wallvik J, Stenke L, Bernell P, Nordahl G, Hippe E, Hast R. Serum erythropoietin (EPO) levels correlate with survival and independently predict response to EPO treatment in patients with myelodysplastic syndromes. Eur J Haematol. 2002;68:180-6. 
Emília CORTESÃO, Rita TENREIRO, Sofia RAMOS, Marta PEREIRA, Paula CÉSAR, José P. CARDA, Marília GOMES, Luís RITO, Emília MAGALHÃES, Ana C. GONÇALVES, Nuno C. e SILVA, Catarina GERALDES, Amélia PEREIRA, Letícia RIBEIRO, José M. NASCIMENTO COSTA, Ana B. Sarmento RIBEIRO

\section{Eritropoietina Sérica como Marcador Prognóstico em Síndrome Mielodisplásica}

Acta Med Port 2015:28:720-725

Publicado pela Acta Médica Portuguesa, a Revista Científica da Ordem dos Médicos

Av. Almirante Gago Coutinho, 151

1749-084 Lisboa, Portugal.

Tel: +351218428215

E-mail: submissao@actamedicaportuguesa.com

www.actamedicaportuguesa.com

ISSN:0870-399X | e-ISSN: 1646-0758

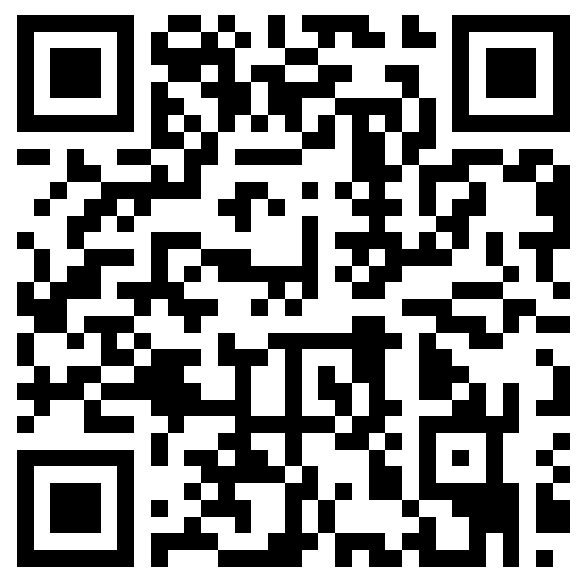

